\title{
Curcolonol suppresses the motility of breast cancer cells by inhibiting LIM kinase 1 to downregulate cofilin 1 phosphorylation
}

\author{
HONG LU ${ }^{1}$, JIE CHEN $^{2}$, YONGMING LUO ${ }^{2}$, HUANJUN XU $^{2}$, LING XIONG $^{2}$ and JIANJIANG FU ${ }^{2}$ \\ ${ }^{1}$ Network and Educational Technology Center, and ${ }^{2}$ Department of Pharmacology, School of Pharmacy, \\ Jiangxi University of Traditional Chinese Medicine, Nanchang, Jiangxi 330004, P.R. China
}

Received December 11, 2017; Accepted August 21, 2018

DOI: 10.3892/ijo.2018.4592

\begin{abstract}
Curcolonol (CCL) is a furan type sesquiterpene isolated from several medical herbs. Based on previous results of anti-migratory activity screening, in this study, we investigated the effects of CCL on cancer cell motility. By in vitro migration assay, we found that CCL significantly inhibited the vertical and horizontal migration of breast cancer cells induced by transforming growth factor (TGF)- $\beta 1$. In addition, CCL also exerted inhibitory effects on F-actin polymerization in breast cancer cells when the cells were dyed with phalloidin. Given the close association between F-actin and ADF/cofilin, the effects of CCL on the expression and phosphorylation of cofilin 1 were explored. It was observed that there were minimal changes in the expression of cofilin 1; however, the phosphorylation of cofilin 1 was significantly inhibited by CCL in a dose-dependent manner. Furthermore, CCL significantly inhibited the activity of LIM kinase 1 (LIMK1), although almost no effects were observed on LIMK1 expression and phosphorylation. However, the inhibitory effects of CCL on LIMK1 activity were antagonized and enhanced by the overexpression and knockdown of LIMK1, respectively. Based on the current data, it is thus suggested that the suppressive effects of CCL on breast cancer cell motility are due to its potential to reduce the phosphorylation of cofilin 1, which may be associated with the inhibition of the catalytic activity of LIMK 1 .
\end{abstract}

\section{Introduction}

The ability of tumor cells to move through tissues is required for local invasion and dissemination from the primary tumor $(1,2)$. Cellular movement depends on the establishment

Correspondence to: Professor Jianjiang Fu, Department of Pharmacology, School of Pharmacy, Jiangxi University of Traditional Chinese Medicine, 818 Meiling Road, Nanchang, Jiangxi 330004, P.R. China

E-mail: jianjiang_fu@yeah.net

Key words: curcolonol, motility, LIM kinase 1, cofilin 1, breast cancer of physical forces by means of protrusive forces and traction forces, leading to membrane extensions and contractions (3). These deformations are driven by the spatially and temporally controlled assembly of the cytoskeleton $(4,5)$. Cell biological analyses have revealed that the actin filament is mainly involved in the generation of the forces responsible for cell motility by elongating or shortening at specific sites on the membrane (5). This type of actin cytoskeleton is regulated by a variety of actin-binding proteins; among these, cofilin 1 plays a critical role in actin filament turnover by interacting with monomeric actin, decreasing the availability of polymerization-competent actin subunits $(6,7)$. The activity of cofilin 1 is controlled by the phosphorylation and deposphorylation at Ser-3 by LIMK family protein kinases $(8,9)$. LIMK family is composed of two members, LIMK1 and LIMK2. Both of these are protein kinases regulating the polymerization of actin and decomposition of microtubules $(10,11)$. Recent findings have strongly indicated that LIMKs play important roles in tumor cell invasion and metastasis (12-14). Therefore, the understanding of the functions of LIMK as regards the fine regulation of the balance between phosphorylated and non-phosphorylated cofilin 1 may aid and accelerate the development of novel therapeutic agents.

Sesquiterpenoids are interesting natural products which have diverse structural frameworks and exhibit a series of activities including anti-inflammatory, anti-fungal and anticancer effects (15). Plants from Chloranthaceae (genus Chloranthus) are important sources of this type of compounds and their dimmers (16). Chloranthushenryl Hemsl. is a perennial herb in this genus native to China, which is distributed in the southern part of mainland China. It is widely used as a 'folk remedy' for lumbocrural pain, bone fractures, pruritus and other ailments (16). In our previous phytochemical and pharmacological investigations into the genus Chloranthus, we found that there were several sesquiterpenoid lactones which exhibited anti-metastatic properties, most of which can inhibit the migration of tumor cells (17-19). Based on these concepts, we focused our research on the finding of chemicals from this genus with the ability to suppress the motility of cancer cells. By migration-inhibition screening, $>70$ chemicals from 4 plants from the genus Chloranthus, including Sarcandra glabra (Thunb.) Nakai, Chloranthus henryi Hemsl., Chloranthus fortunei and Chloranthus multistachys, were investigated. In the current study, we reported that 
curcolonol (CCL), a furan type sesquiterpene isolated from Chloranthushenryl Hemsl., suppressed the migration of breast cancer cells by downregulating LIMK1 activity.

\section{Materials and methods}

Materials. HPLC grade CCL was purchased from Chroma Biotechnology Co. Ltd. (Chengdu, China; cat. no. 217817-09-9; chemical structure shown in Fig. 1). A stock solution (1 mM) was prepared by dissolving CCL in dimethyl sulfoxide (DMSO). Recombinant human transforming growth factor (TGF)- $\beta 1$ (PHG9211) was a product of Life Technologies/Thermo Fisher Scientific (Waltham, MA, USA), and recombinant cofilin 1 was purchased from Abcam (Cambridge, MA, USA; cat. no. ab85154). BB-94 (Santa Cruz Biotechnology, Inc., Santa Cruz, CA, USA; cat. no. SC-203833), a broad spectrum matrix metalloproteinase (MMP) inhibitor, served as a positive control in the cell migration assay. Alexa Fluor ${ }^{\mathrm{TM}}$ 488 Phalloidin was purchased from Thermo Fisher Scientific (cat. no. A12379). The TGF- $\beta$ RI kinase inhibitor, SD-208 (Sigma-Aldrich, Beijing, China; cat. no. 627536-09-8), was used as a positive control in the F-actin dying assay. Recombinant human cofilin 1 (ab95396) protein was purchased from Abcam.

Antibodies and plasmids. Rabbit polyclonal antibodies against cofilin 1 (ab42824), p-cofilin 1 (ab12866), LIMK1 (ab81046) and rabbit polyclonal to LIM kinase 1 (phospho T508, ab38508) were purchased from Abcam. Mouse monoclonal antibody against $\beta$-actin (sc-130301) is a product of Santa Cruz Biotechnology. Mouse monoclonal antibody against Vimentin (sc-73258) was also obtained from Santa Cruz Biotechnology. The pIRES2-LIMK1 eukaryotic expression plasmid and the pIRES2-enhanced green fluorescent protein empty vector were kindly provided by Professor Hongbo Wang from Yan Tai University (Yan Tai, China). Small interfering RNA (siRNA) against cofilin 1 (sc-35078) and LIMK1 (sc-35810) are products of Santa Cruz Biotechnology. Control siRNA-1 (sc37007) was used as a negative control in the RNA interference (RNAi) experiments.

Cell culture. The human breast adenocarcinoma cell lines, MDA-MB-231 and MDA-MB-468, purchased from the Cell Resource Center, Institute of Basic Medical Sciences, Chinese Academy of Medical Sciences (Beijing, China), and were maintained in DMEM (Sigma-Aldrich) with $2 \mathrm{mM}$ glutamine and $15 \% \mathrm{FCS}$ at $37^{\circ} \mathrm{C}$ in $1 \% \mathrm{CO}_{2}$.

Vertical migration of breast cancer cells. Firstly, the migratory capability of the cells was assessed using an AP 48 chamber (Neuro Probe, Inc., Gaithersburg, MD, USA). Briefly, the rough (lower) surface of the polycarbonate membrane $(8-\mu \mathrm{m}$ pore size) was coated with $10 \mu \mathrm{g}$ of fibronectin in a volume of $50 \mu \mathrm{l}$ overnight at $4^{\circ} \mathrm{C}$. Subsequently, the breast cancer cells $\left(2 \times 10^{5}\right)$ in $100 \mu \mathrm{l}$ serum-free DMEM, which contained the vehicle (DMSO), positive control or indicated concentrations of CCL were plated in the upper chambers, while the lower part contained $30 \mu \mathrm{l}$ DMEM, including 10\% serum and $10 \%$ collagen I. The chambers were incubated for $18 \mathrm{~h}$ at $37^{\circ} \mathrm{C}$. Following incubation, the cells which had not migrated through the membrane pores were discarded by wiping with a cotton swab. After being fixed and stained with crystal violet (Sigma-Aldrich; final concentration, $0.5 \mathrm{~g} / \mathrm{ml}$ ). Images of the migrating cells were captured under a microscope (Leica DM 3000B; Leica Microsystems, Wetzlar, Germany) and the migrating cells were then quantified with Image Pro plus software 5.0 (Media Cybernetics Inc.). The representative results are illustrated in the figures. Each assay was performed in triplicate.

Horizontal migration of breast cancer cells. Subsequently, the migration of the breast cancer cells was monitored in real-time using the ORIS ${ }^{\mathrm{TM}}$ cell migration assay system (Platypus Technologies, Madison, WI, USA). Log-phase cells were harvested, and resuspended to a final concentration of $1 \times 10^{6} / \mathrm{ml}$ in FBS-free DMEM. A total of $100 \mu \mathrm{l}$ of suspended cells was plated into each well through one of the side ports of the Oris ${ }^{\mathrm{TM}}$ Cell Seeding Stopper. The plate containing Stoppers was incubated in a humidified chamber $\left(37^{\circ} \mathrm{C}\right.$, $5 \% \mathrm{CO}_{2}$ ) for $12 \mathrm{~h}$ to permit cell attachment. The stoppers and media were removed, respectively. Subsequently, $100 \mu 1$ of FBS-free medium containing Calcein AM (Sigma-Aldrich, final concentration $0.5 \mu \mathrm{g} / \mathrm{ml}$ ) was added, and incubated in a humidified chamber $\left(37^{\circ} \mathrm{C}, 0.5 \% \mathrm{CO}_{2}\right)$ for $40 \mathrm{~min}$. Images were captured under a fluorescence microscope (Leica DM 3000B; Leica Microsystems, Wetzlar, Germany), and these data served as an initial control. Following fluorescence intensity examination, the media were removed gently, and washed with PBS twice. Subsequently, $200 \mu 1$ of full medium containing the vehicle (DMSO), $10 \mathrm{nM} \mathrm{BB}-94$ or indicated concentrations of CCL was added, and the cells were incubated for $24 \mathrm{~h}$ at $37^{\circ} \mathrm{C}$. At the end point of treatment, data were obtained with the same methods mentioned above.

Phalloidin dying of F-actin. Log-phase MDA-MB-231 cells were harvested and resuspended. A total of $300 \mu \mathrm{l}$ of suspended cells was then pipetted into each well of Lab-Tek ${ }^{\circledR}$ 16-well Chamber Slides (Electron Microscopy Sciences, Hatfield, PA, USA) at a density of $1 \times 10^{5} / \mathrm{ml}$. After being subjected to the treatments with the vehicle (DMSO), TGF- $\beta$ $(10 \mathrm{ng} / \mathrm{ml}), \mathrm{SD}-208(50 \mathrm{nM})$ or CCL $(5 \mu \mathrm{M})$ for $24 \mathrm{~h}$, the cells were fixed with $4 \%$ paraformaldehyde (Sigma-Aldrich) in cytoskeleton buffer with sucrose (CBS) [10 mM MES, pH 6.1, $138 \mathrm{mM} \mathrm{KCl}, 3 \mathrm{mM} \mathrm{MgCl}{ }_{2}, 10 \mathrm{mM}$ EGTA and $0.32 \mathrm{mM}$ sucrose] for $30 \mathrm{~min}$ at room temperature. The cells were permeabilized with $0.1 \%$ Triton X-100 in PBS for 7 min and blocked with $1 \%$ BSA in PBS for $1 \mathrm{~h}$ at $37^{\circ} \mathrm{C}$. Between each step described above, the cells were washed 3 times with PBS 5 min each. To visualize the actin cytoskeleton, F-actin was stained with Alexa Fluor ${ }^{\mathrm{TM}} 488$ Phalloidin in CBS for $1 \mathrm{~h}$. The cells were then counterstained with $4 \mathrm{mg} / \mathrm{ml}$ 4,6-diamidino2-phenylindole (DAPI; Sigma-Aldrich) and the samples were mounted for fluorescence microscopy (Olymbus BX-63; Olympus, Tokyo, Japan) examination.

Overexpression of LIM kinaseland siRNA-mediated gene silencing. For the overexpression of LIMK1, the MDA-MB-231 cells were transiently transfected with the pIRES2-LIMK1 eukaryotic expression plasmid and pIRES2-enhanced green fluorescent protein empty vector using Plasmid Transfection 
Reagent (sc-108061; Santa Cruz Biotechnology) according to the manufacturer's instructions. The cells were then maintained for $24 \mathrm{~h}$ at $37^{\circ} \mathrm{C}$ before being harvested for further analyses. For gene silencing, at $24 \mathrm{~h}$ prior to transfection, the MDA-MB-231 cells were seeded in a 6-well plate in triplicate at a concentration so that the following day the cells reached $70-80 \%$ confluency. Transfection was performed at a final concentration of $200 \mathrm{nM}$ using siRNA Transfection Reagent (sc-29528; Santa Cruz Biotechnology) following the manufacturer's instructions. The cells were used at $48 \mathrm{~h}$ following transfection in the further experiments.

Immunoprecipitation and kinase assay. The MDA-MB-231 and MDA-MB-468 cells were treated with the indicated concentrations of CCL and stimulated with $10 \mathrm{ng} / \mathrm{ml}$ TGF- $\beta 1$ for $24 \mathrm{~h}$. The cells were then harvested and lysed in radioimmunoprecipitation (RIPA) lysis buffer (50 mM Tris- $\mathrm{HCl} \mathrm{pH} 7.5$, $150 \mathrm{mM} \mathrm{NaCl}, 50 \mathrm{mM} \mathrm{NaF}, 1 \% \mathrm{NP}-40,0.1 \%$ sodium deoxycholate and $1 \mathrm{mM}$ sodium pyrophosphate) with protease and phosphatase inhibitors for $30 \mathrm{~min}$ on ice. Following centrifugation $\left(10,000 \mathrm{x} \mathrm{g}\right.$ for $15 \mathrm{~min}$ at $\left.4^{\circ} \mathrm{C}\right)$ to remove the debris, the supernatants were incubated with the anti-LIMK1 antibody and protein G-Agarose beads (Santa Cruz Biotechnology) for $4 \mathrm{~h}$ at $4^{\circ} \mathrm{C}$. The immunoprecipitates were washed 3 times with lysis/kinase buffer and subjected to an in vitro kinase reaction. In vitro kinase reactions were performed in $20 \mu \mathrm{l}$ of the kinase buffer containing $15 \mu \mathrm{M}$ ATP, $5 \mu \mathrm{Ci}$ of $\left[\gamma^{32} \mathrm{P}\right]-\mathrm{ATP}$ (5,000 Ci/mmol; Amersham Biosciences, Little Chalfont, UK) supplemented with $2 \mu \mathrm{g}$ of recombinant cofilin 1 at $30^{\circ} \mathrm{C}$ for $30 \mathrm{~min}$. The reactions were terminated by the addition of SDS sample buffer. Proteins were electrophoresed by $10 \%$ SDS-PAGE and transferred onto nitrocellulose membranes, and analyzed by autoradiography using a BAS1000 Bio-image analyzer (Fuji Film, Tokyo, Japan), and by western blot analysis with anti-cofilin 1, anti-LIMK1 and anti-p-LIMK1 antibodies.

Kinase-Glo ${ }^{\circledR}$ luminescent kinase assay. LIM kinase1 activity was also determined with the Kinase-Glo Plus luminescent kinase assay (Promega, Madison, WI, USA). The principle of this assay is to evaluate kinase activity by quantifying the amount of ATP remaining after a kinase reaction, which is determined by a luciferase-catalyzed reaction. The LIMK1 reaction and the following luciferase reaction were performed in a 96-well plate. The MDA-MB-231 cells were treated with vehicle (DMSO) or $2.5,5$ or $10 \mu \mathrm{M} \mathrm{CCL}$ and stimulated with $10 \mathrm{ng} / \mathrm{ml}$ TGF- $\beta 1$ for $24 \mathrm{~h}$. The cells were then harvested and lysed in lysis/kinase buffer (50 mM HEPES, pH 7.4, $150 \mathrm{mM}$ $\mathrm{NaCl}, 0.5 \% \mathrm{NP}-40,5 \%$ glycerol, $1 \mathrm{mM} \mathrm{MgCl}{ }_{2}, 1 \mathrm{mM} \mathrm{MnCl}{ }_{2}$, $10 \mathrm{mM} \mathrm{NaF}, 1 \mathrm{mM} \mathrm{Na} \mathrm{VO}_{4}, 1 \mathrm{mM}$ dithiothreitol, $1 \mathrm{mM}$ phenylmethylsulfonyl fluoride and $10 \mu \mathrm{g} / \mathrm{ml}$ leupeptin) for $30 \mathrm{~min}$ on ice. Following centrifugation $\left(10,000 \mathrm{x}\right.$ g for $15 \mathrm{~min}$ at $\left.4^{\circ} \mathrm{C}\right)$ to remove the debris, $50 \mu \mathrm{l}$ supernatant were added to each well. Subsequently, $50 \mu \mathrm{l}$ of recombinant cofilin 1 (25 nM, final concentration) in kinase buffer (50 mmol/1 HEPES, pH 7.3, $\left.10 \mathrm{mmol} / 1 \mathrm{MgCl}_{2}, 0.1 \% \mathrm{BSA}, 2 \mathrm{mmol} / \mathrm{l} \mathrm{DTT}\right)$ were added to each well. A total of $10 \mu \mathrm{l}$ ATP $(1 \mu \mathrm{M}$, final concentration) was then added to initiate the kinase reaction. The reaction mixture was maintained at $30^{\circ} \mathrm{C}$ for $2 \mathrm{~h}$ in a water bath. The mixture was then placed at room temperature for $10 \mathrm{~min}$. Subsequently, $50 \mu 1$ of Kinase-Glo Assay Plus reagent were added to initiate the luciferase reaction. Luminescence was detected with the VICTOR3 multilabel counter (PerkinElmer, Waltham, MA, USA) following a 10-min incubation.

Western blot analysis. The breast cancer cells were treated with the indicated concentrations of CCL for $24 \mathrm{~h}$. The cells were then harvested and lysed in lysis buffer (Beyotime Biotech, Shanghai, China). The concentration of the protein in the lysates was then determined using a BCA kit (Beyotime Biotech). Aliquots of each lysate containing equal quantities of protein (ranging between 500 and 1,000 $\mu \mathrm{g}$ between experiments) were added to SDS-PAGE gels (ranging between 8 and 12\%), and then transferred onto hybond nitro blotting membranes and subjected to western blot analysis. The membranes were blocked with 5\% non-fat dried milk for $1 \mathrm{~h}$ at room temperature and subsequently incubated with primary antibody overnight at $4^{\circ} \mathrm{C}$. Following washing 3 times with TTBS, the membranes were incubated with the secondary antibody for $2 \mathrm{~h}$ at room temperature. The immunoreactive bands were detected using an enhanced chemiluminescence kit (Beyotime Biotech). $\beta$-actin $(1: 1,000)$ served as an internal control. The signal intensities of the bands of interest were quantified and normalized to $\beta$-actin using the Image-Pro Plus software version 6.0 (Media Cybernetics, Inc.). The primary antibodies used in the present study were as follows: Rabbit polyclonal antibodies against cofilin 1 (1:1,000; ab42824), p-cofilin 1 (1:1,000; ab12866), LIMK1 (1:1,000; ab81046), rabbit polyclonal to LIM Kinase 1 (1:1,000; phospho T508, ab38508) (all from Abcam) and mouse monoclonal antibody against Vimentin (1:1,000; sc-73258; Santa Cruz Biotechnology, Inc.). The secondary antibodies used in the present study were as follows: Goat polyclonal secondary antibody to mouse IgG $(1: 5,000 ;$ ab6789) and goat anti-rabbit $\operatorname{IgG}(1: 5,000 ;$ ab6721) (both from Abcam).

Immunofluorescence analysis. Vimentin immunofluorescence in the breast cancer cells was analyzed using an immunofluorescence staining kit (Beyotime Biotech). Briefly, the cells were plated into wells of 8-well-Chamber Slide System (Nunc $^{\circledR}$; Thermo Fisher Scientific), and treated with $5 \mu \mathrm{M}$ CCL and/or the vehicle (DMSO) for $24 \mathrm{~h}$. At the end of the treatment, the cells cultured on fibronectin-coated slides were fixed with $3.7 \%$ paraformaldehyde-phosphate-buffered saline followed by incubation with $0.5 \%$ Triton X-100 for $5 \mathrm{~min}$ at room temperature. After being washed with PBS and blocked, the slides were triple-stained with vimentin primary antibody, anti-mouse IgG conjugated with FITC (4413; 1:500; Cell Signaling Technology, Danvers, MA, USA) and ProLong Gold anti-fade reagent with DAPI (Thermo Fisher Scientific). The samples were examined under a fluorescent microscope (OlympusBX63; Olympus).

Statistical analysis. The data are presented as the means \pm SD and were analyzed using the SPSS for Windows (13.0) software program (SPSS Inc., Chicago, IL, USA). Comparisons among different groups were carried out by one-way analysis of variance (one-way ANOVA) and the Fisher's LSD test was used as a post hoc test following one-way ANOVA. P-values 0.05 and 0.01 were assumed as the level of significance for the statistic tests carried out. 


\section{Results}

CCL attenuates the migratory capacity of breast cancer cells. First, we investigated the effects of CCL (chemical structure shown in Fig. 1) on cell migration using an AP 48 chamber system. TGF- $\beta 1(10 \mathrm{ng} / \mathrm{ml})$ was used to mimic the growth environment of cancer cells in vivo. It was shown that CCL supplementation had a significant inhibitory effect on the migration of the breast cancer cells (Fig. 2A). Compared with vehicle-treated cells, the addition of TGF- $\beta 1$ led to an obvious enhancement the migration of both the MDA-MB-231 and MDA-MB-468 cells. When the cells were cultured in presence of BB-94 for $18 \mathrm{~h}$, both of the breast cancer cell lines exhibited an obvious decrease in cell migration compared with the TGF- $\beta 1$-treated group. Following culture in the presence of CCL for $18 \mathrm{~h}$, both breast cancer cells exhibited a weaker motility. The migration rates of the MDA-MB-231 cells were $66.94,22.08$ and $12.00 \%$ at concentrations of $2.5,5$ and $10 \mu \mathrm{M}$ of CCL, respectively. The migration of the MDA-MB-468 cells was also significantly blocked by CCL (Fig. 2A). Consistent with these findings, the real-time migration monitoring data from the ORIS ${ }^{\mathrm{TM}}$ cell migration assay system indicated a dose-dependent decrease in cell migration following the supplementation of CCL in both the MDA-MB-231 and MDA-MB-468 cells (Fig. 2B). Thus, these results suggested that exposure to $\mathrm{CCL}$ decreased the migratory potential of the breast cancer cells.

CCL impairs actin cytoskeleton organization in MDA-MB-231 cells. We then investigated the effects of CCL on F-actin microfilaments in the MDA-MB-231 cells. FITC-labeled phalloidin clearly labeled the F-actin in the fixed and permeabilized cells, as described in a range of earlier reports $(4,5)$. As shown in Fig. 3, the vehicle-treated cells exhibited a regular aggregation of F-actin present along the cells. When the cells were induced with TGF- $\beta 1$, this phenomenon became more pronounced. The addition of TGF- $\beta 1$ resulted in the increased expression of F-actin and in the formation of stress fibers at the cell perimeter. Furthermore, there was an additional appearance of F-actin-rich microspikes protruding from the cell periphery, which formed lamellipodia. When the cells were treated with $50 \mathrm{nM}$ SD-208, a TGF- $\beta$ R inhibitor, there were a significant reduction in F-actin fiber expression and a disruption of F-actin arrangement inside the cells. However, there were no obvious effects on the formation of lamellipodia at the cell perimeter. When the cells were treated with CCL, we observed not only a decrease in F-actin fiber expression and the disruption of its arrangement, but also the disappearance of lamellipodia around the cells. The cells became smooth at the cell perimeter. Therefore, it seems clear that the inhibitory effects of CCL on cell migration have a very close association with the disorganization of F-actin.

CCL disrupts actin cytoskeletal proteins in breast cancer cells. We then analyzed the expression and phosphorylation of cofilin 1, a well-known actin depolymerizing factor (ADF) by western blot analysis (Fig. 4). Our results revealed that, compared with the TGF- $\beta 1$-stimulated cells, CCL treatment, as well as cofilin 1 knockout, decreased the expression of p-cofilin 1 in a dose-dependent manner in

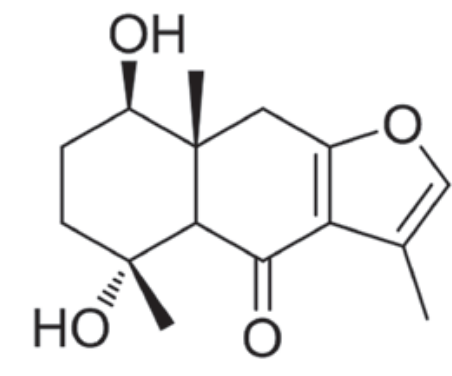

\section{Curcolonol MW: 264}

Figure 1. Molecular structure of curcolonol.

both the MDA-MB-468 cells (Fig. 4A) and MDA-MB-231 cells (Fig. 4B). However, only were weak inhibitions of the expression of cofilin 1 in both breast cancer lines were observed.

CCL suppresses LIMK1 activity in breast cancer cells. By kinase-Glo ${ }^{\circledR}$ luminescent kinase assay, we then examined the effects of CCL on LIMK1. We demonstrated that the consumption of ATP in this assay system was significantly decreased after the supplementation of CCL in the MDA-MB-231 cells. These data indicated that the inhibitory effects of CCL on cofilin 1 may be related to changes inLIMK1activity (Fig. 5A). To further distinguish these findings, we analyzed LIMK1 activity by co-immunoprecipitation and autoradiographybased assay. LIMK1 was purified by immunoprecipitation and subjected to kinase assays in the presence of $\left[\gamma^{-32} \mathrm{P}\right]-\mathrm{ATP}$, cofilin 1 and indicated concentrations of CCL. CCL exerted an inhibitory effect on cofilin 1 phosphorylation, but a weak inhibitory effect on the physical interaction and expression of cofilin 1 and LIMK1. In addition, there was no obvious inhibition on the phosphorylation of LIMK1. Taken together, our data strongly suggested that CCL exerted marked inhibitory effects on the catalytic activity of LIMK1, but not on LIMK1 expression and phosphorylation.

Overexpression of LIMK1 weakens the effects of $C C L$ on MDA-MB-231 cells. To further investigate the effects of CCL on LIMK1 activity, we constructed a transient LIMK1-overexpressing MDA-MB-231 cell line and examined the impact of CCL on cofilin 1 expression and cell migration (Fig. 6). In the empty vector group and LIMK1 overexpression group, no obvious changes were observed in the expression of total cofilin 1 compared to the control group. However, a significant increase in the phosphorylation level of cofilin 1 was observed when the cells were transiently transfected with the LIMK1 overexpression plasmid. Following treatment with CCL for $24 \mathrm{~h}$, we found that the expression of p-cofilin 1 in the LIMK1-overexpressing cells was blocked by CCL, although there was no clear change in cofilin 1 expression (Fig. 6A and B). We then investigated the effects of CCL on the migration of LIMK1-overexpressing cells. It was found that the migratory capacity of the cells was markedly increased in the LIMK1-overexpressing group compared with the empty vector group (Fig. 6C), when the cells were treated with CCL for $24 \mathrm{~h}$. This indicates that LIMK1 can neutralize the inhibitory effects of CCL on cell migration. We also 
A
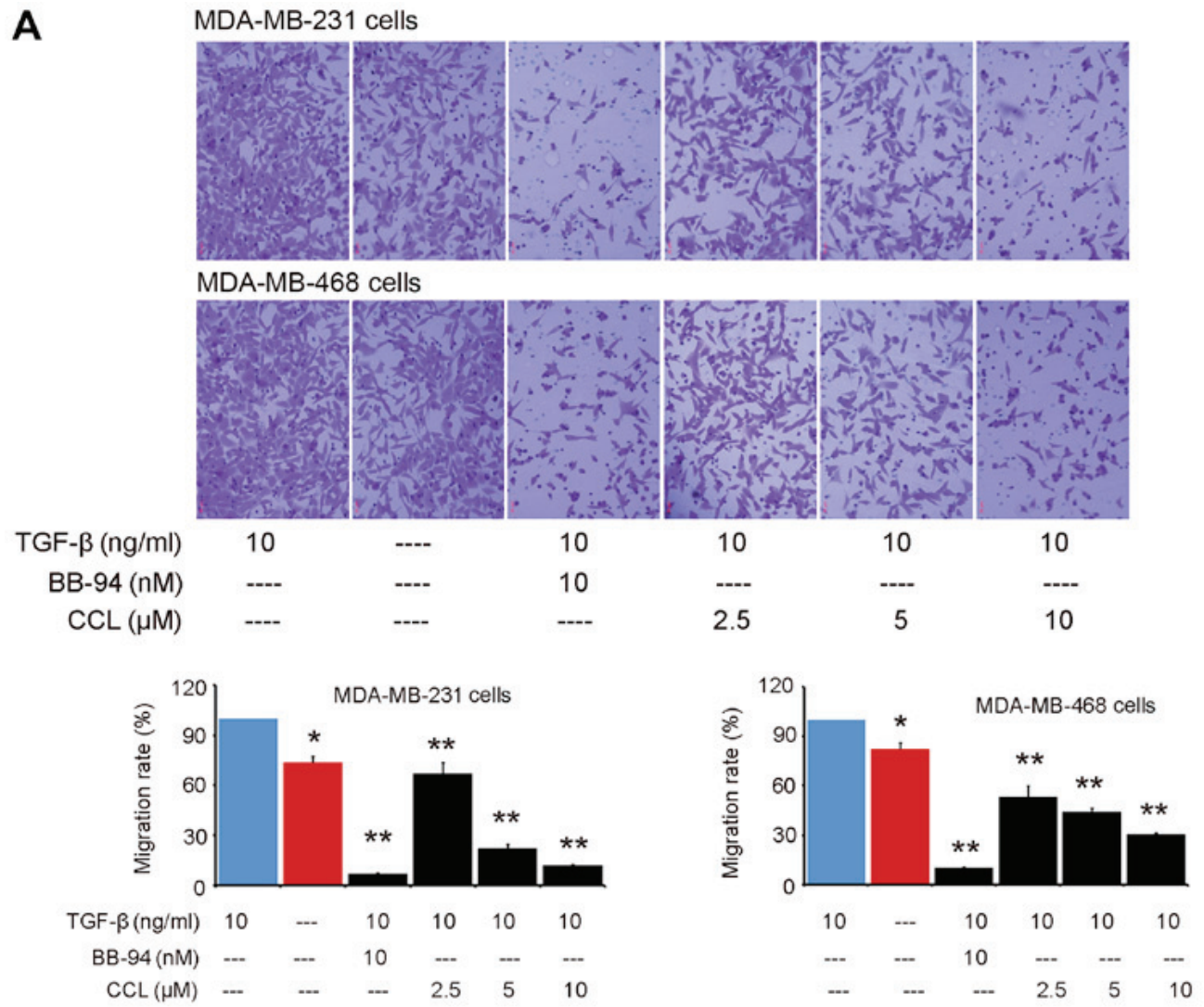

B MDA-MB-231 cells
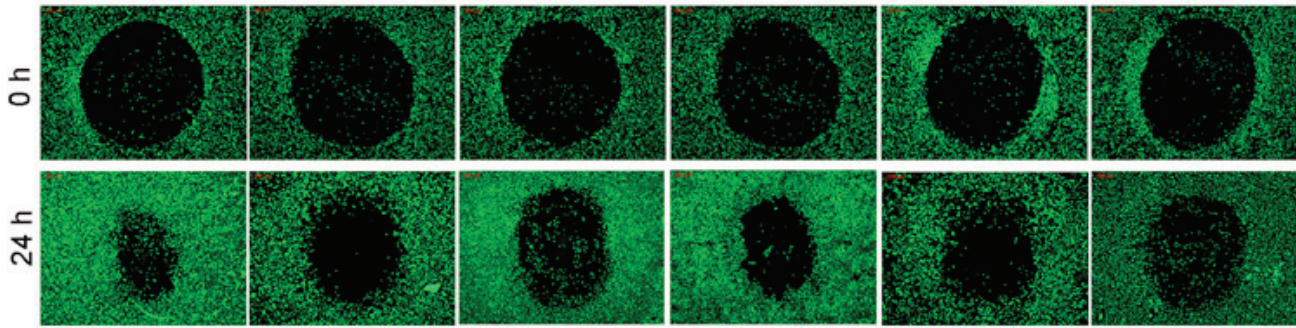

MDA-MB-468 cells
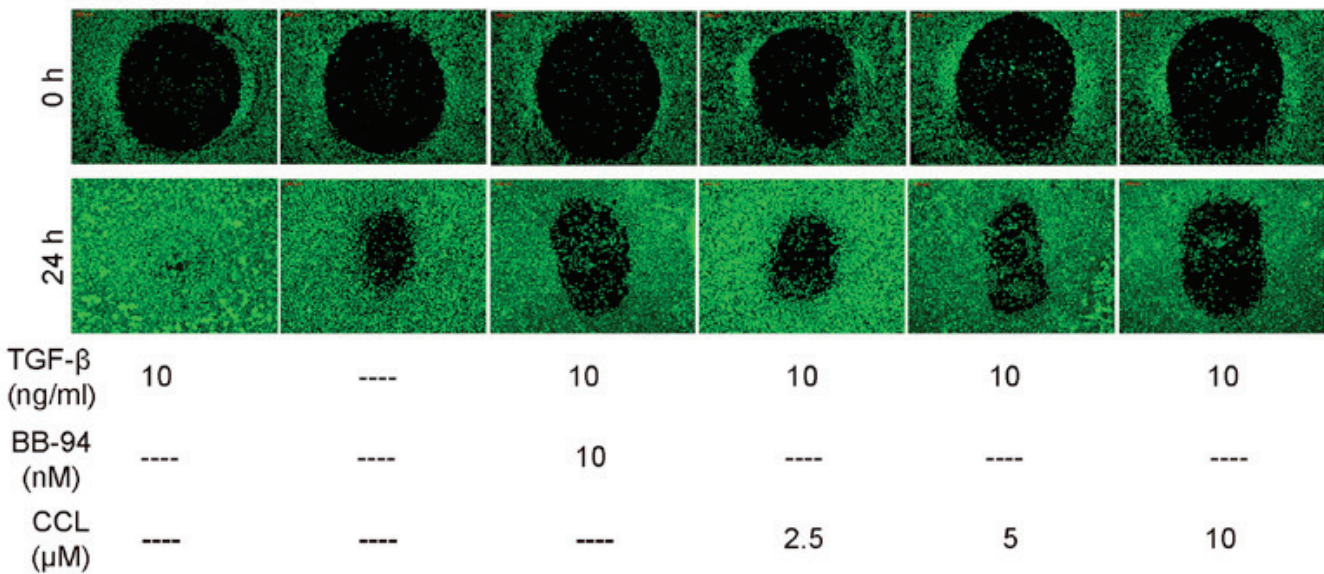

10

10

10

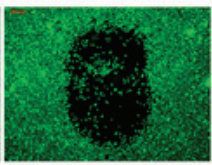

10

2.5

5

10

Figure 2. Effects of CCL on the migration of breast cancer cells. (A) Effects of CCL the vertical migration of breast cancer cells determined by the AP 48 chamber system; (B) Effects of CCL the horizontal migration of breast cancer cell determined by the ORIS ${ }^{\mathrm{TM}}$ cell migration assay system. Each assay was performed in triplicate. Vehicle (DMSO) was used as a CTRL, and BB-94, a broad spectrum MMP inhibitor, served as a positive control. ${ }^{*} \mathrm{P}<0.05$, ${ }^{* *} \mathrm{P}<0.01$ compared with TGF- $\beta$ treatment alone. CTRL, control; TGF- $\beta$, transforming growth factor- $\beta$; CCL, curcolonol.

analyzed the expression of vimentin, a mesenchymal-specific molecular mark by immunofluorescence analysis, when the LIMK1-overexpressing cells were treated with CCL. Similarly,
LIMK1overexpression enhanced vimentin expression and antagonized the effects of CCL on vimentin expression in the MDA-MB-231 cells (Fig. 7). 

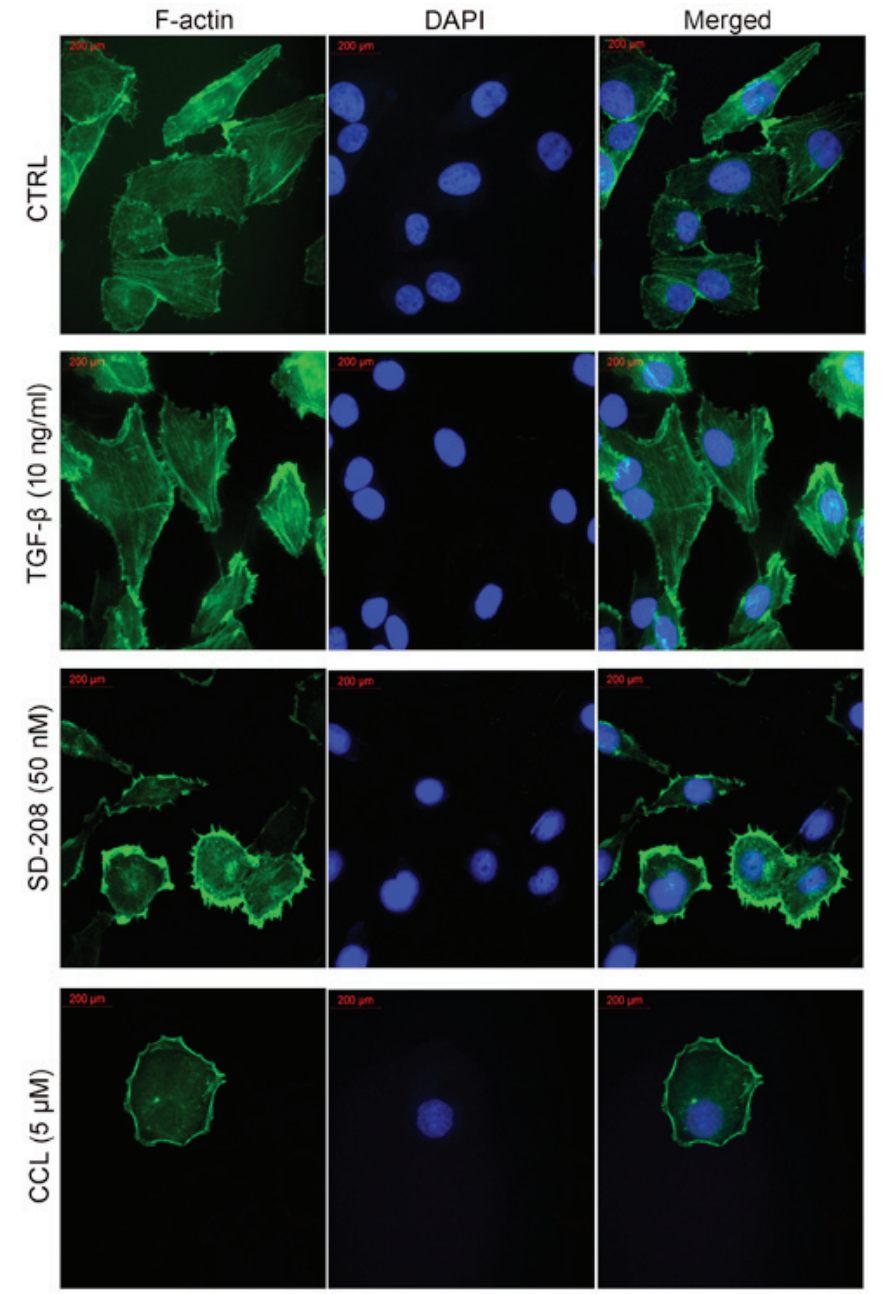

Figure 3. Effects of CCL on F-actin assembly in the MDA-MB-231 cells Each assay was performed in triplicate. Vehicle (DMSO) was used as a CTRL, and SD-208, a TGF- $\beta$ R I kinase inhibitor served as the positive control. CTRL, control; CCL, curcolonol.

Downregulation of LIMK1 enhances the effects of CCL on MDA-MB-231 cells. To confirm that LIMK1 was the critical target of CCL, LIMK1 was knocked down by means of siRNA. Based on the results of western blot analysis, the knockdown of LIMK1 significantly inhibited the phosphorylation of cofilin 1 , but did not affect total cofilin 1 expression. The supplementation of CCL augmented the inhibitory effects of LIMK1 on cofilin 1 phosphorylation (Fig. 8A and B). Moreover, CCL enhanced the effects of LIMK1-siRNA on cell activities. As shown in Figs. 8C and 9, cell migration and vimentin expression were significantly inhibited by CCL in the MDA-MB-231 cells and the knockdown of LIMK1 by siRNA exerted more potent suppressive effects. Taken together, these data indicated that the effects of CCL on cell migration and cofilin 1 phosphorylation, are associated with the suppression of LIMK1 activity.

\section{Discussion}

Chloranthus henryl is a perennial herb, which is mainly distributed in the southern part of mainland China. It is widely used as a 'folk remedy' for lumbocrural pain, bone fractures, pruritus and other ailments (16). In our previous studies, it was found that codonolactone, one of the sesquiterpenes extracted from this herb, exhibited anti-metastatic properties. We confirmed that codonolactone significantly suppressed the lung metastatic foci formation of breast cancer in vivo and inhibited the f invasive and migratory abilities of metastatic breast cancer cells. Furthermore, it was also proven that this natural compound impaired TGF- $\beta 1$-induced EMT and the motility of breast cancer cells (17-19). Therefore, in this study, we focused our interests on the anti-metastatic activity and the probable mechanisms of action of sesquiterpenes from this traditional medical herb. Based on the previous data of antimigratory activity screening (20), we investigated the effects of CCL on cancer cell motility.

By an AP 48 chamber system and ORIS ${ }^{\mathrm{TM}}$ cell migration assay system, we first confirmed that CCL attenuated the migratory capacity of breast cancer cells. Cell migration is governed by multiple coordinated mechanisms which can influence the metastatic potential of breast cancer cells. These processes involve the reorganization of cell adhesion complexes and components of the cytoskeleton. One of the rate-limiting steps in this mechanism is F-actin microfilament organization. Actin is a key component of the cytoskeleton and plays an important role in multitude cellular functions, such as cell membrane dynamics, cell shape control, movement and polarity (5). There are two types of actin in cells, monomeric form (G-actin) and filamentous form (F-actin) (21). One of the properties of actin protein is the highly dynamics turnover between G-actin and F-actin, and lead to rapid filament polymerization and depolymerization, which is the rate-limiting step of cell movement (21). In light of the effects of CCL on breast cancer cell migration, in this study, we investigated the effects of CCL on F-actin microfilaments in MDA-MB-231 cells. We certified that CCL significantly impaired the arrangement of F-actin in the MDA-MB-231 cells.

Studies have confirmed that the process of F-actin microfilaments organization is tightly controlled by a serial of actin-binding proteins, including actin depolymerizing factor $(\mathrm{ADF}) /$ cofilin family, which are essential for eukaryotes, and important in actin filament dynamics in cells $(22,23)$. Cofilin 1 , an important member of the $\mathrm{ADF} /$ cofilin 1 family, is widely recognized for its ability to regulate actin polymerization by severing filaments and enhancing their depolymerization. Studies have suggested that cofilin 1 contributes to cancer development, tumor progression, invasion and metastasis. The activity of cofilin 1 is predominantly regulated by phosphorylation on Ser3 by LIMKs, which can block cofilin 1 activity of severing F-actin and results in an increase in cell motility and invasion. Conversely, the dephosphorylation of Ser3 results in the activation of cofilin $1(24,25)$. Lee et al (26) proved that the overexpression of cofilin 1 led to a decrease in the invasive abilities of human lung cancerH1299 cells, which was also confirmed by other groups $(27,28)$. In the present study, we found that CCL decreased p-cofilin 1 and increased non-pcofilin 1 expression. Taken together, our data strongly indicate that the inhibition of CCL on cell migration may be associated with its effects on cofilin 1phosphorylation.

LIM kinase 1 is a serine protein kinase influencing actin cytoskeletal dynamics. There are 39,499 base pairs with 16 exons in the LIMK1 gene which is located on human chromosome 7q11.23. The LIMK1 protein contains two 
A MDA-MB-468 cell

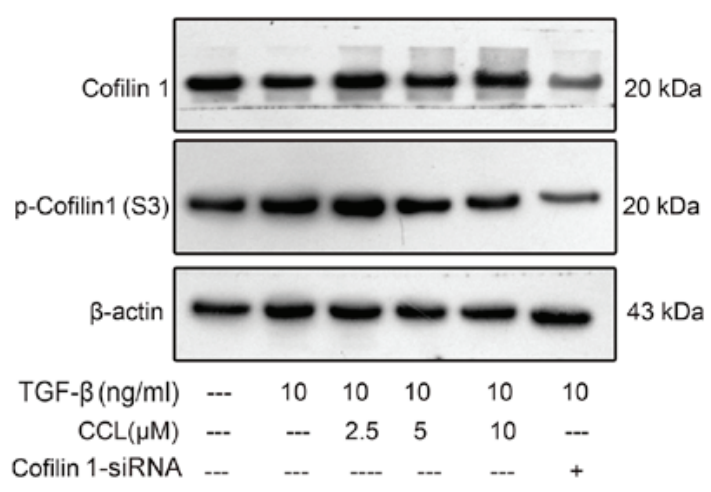

B MDA-MB-231 cell

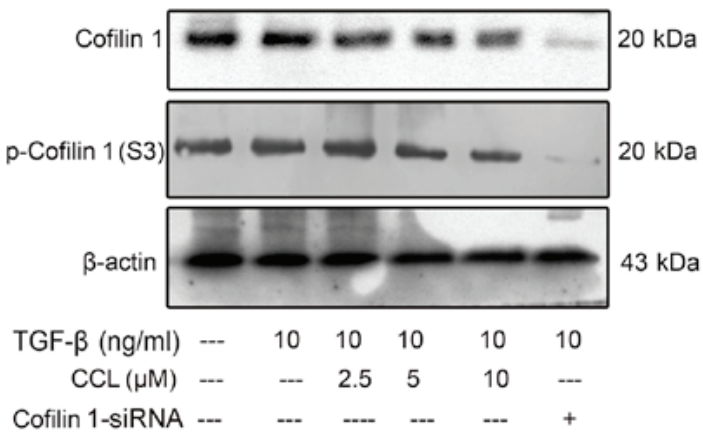

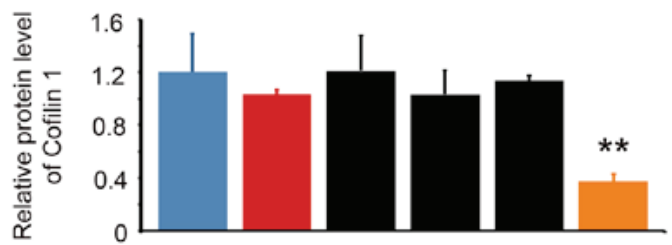

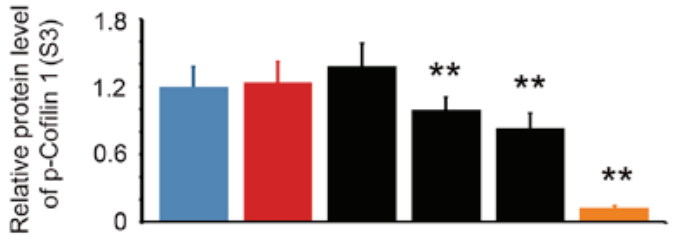

TGF- $\beta$ (ng/ml) $\quad---\quad 10 \quad 10 \quad 10 \quad 10 \quad 10$

CCL $(\mu \mathrm{M}) \quad---\quad--\quad 2.5 \quad 5 \quad 10 \quad--$ Cofilin 1-siRNA --- --- --- ---
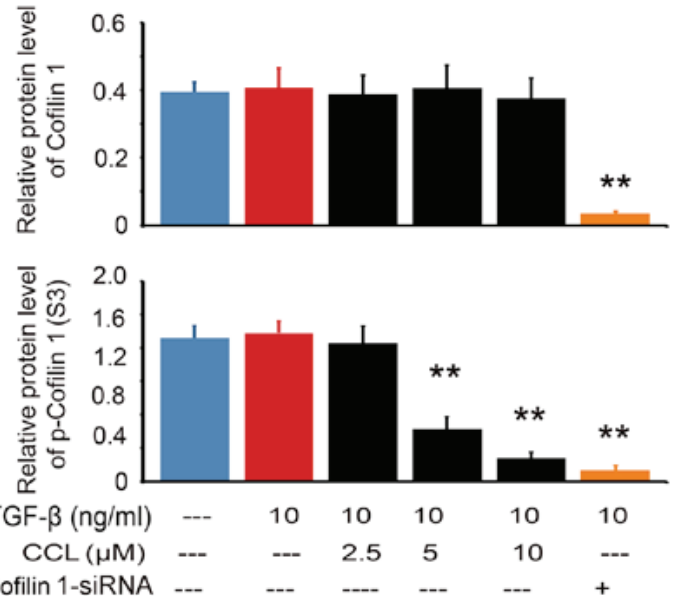

Figure 4. Effects of CCL on the expression of cofilin 1 and p-cofilin 1 in breast cancer cells. (A) Effects of CCL on the expression of cofilin 1 and p-cofilin 1 in MDA-MB-468 cells; (B) Effects of CCL on the expression of cofilin 1 and p-cofilin 1 in MDA-MB-231 cells. ${ }^{* *} \mathrm{P}<0.01$ compared with TGF- $\beta$ alone. Whole-cell extracts were prepared and examined by western blot analysis, and $\beta$-actin was used as an internal control. siRNA against cofilin 1 was used to silence the cofilin 1 gene in the MDA-MB-231 cells, and these cells served as a positive control. CTRL, control; TGF- $\beta$, transforming growth factor- $\beta$; CCL, curcolonol; cofilin 1-siRNA, cofilin 1 small interfering RNA.

A

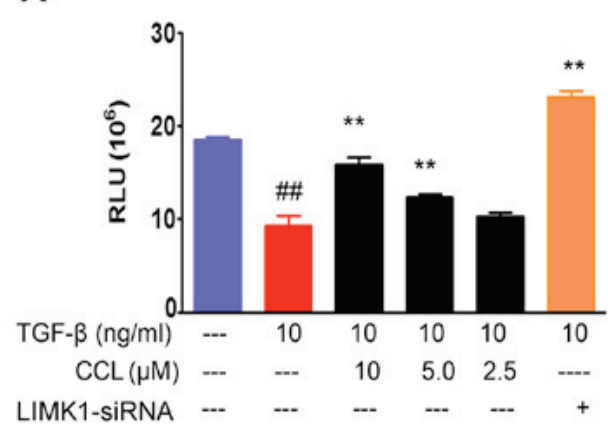

B

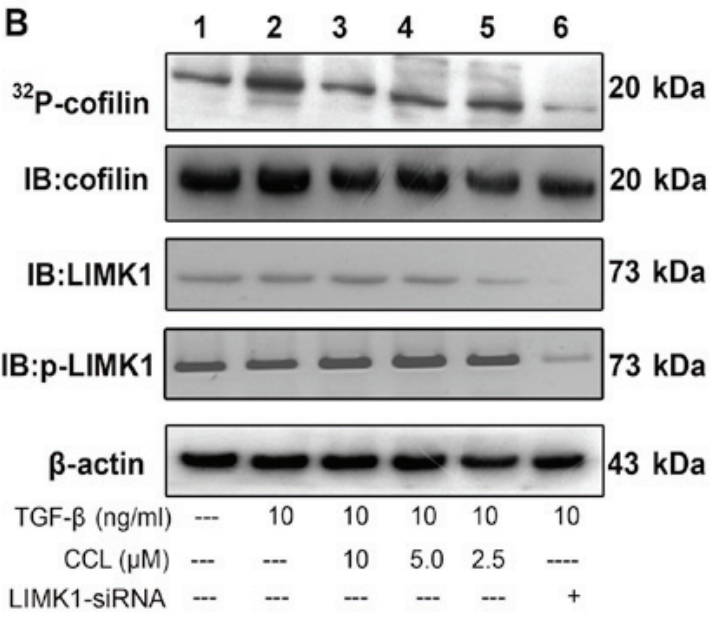

Figure 5. Effects of CCL on LIMK1 activity in MDA-MB-231 cells. (A) Analysis of LIMK1 activity by Kinase-Glo ${ }^{\circledR}$ luminescent kinase assay; (B) analysis of LIMK1 activities by immunoprecipitation and kinase assay. ${ }^{* *} \mathrm{P}<0.01$ compared with TGF- $\beta$ alone; ${ }^{\# \#} \mathrm{P}<0.01$ compared with the CTRL. Vehicle (DMSO) was used as a negative control, and TGF- $\beta 1$ served as the positive control. Cells which were transiently transfected LIMK1-siRNA served as a positive control. Each assay was performed in triplicate. CTRL, control; TGF- $\beta$, transforming growth factor- $\beta$; CCL, curcolonol; LIMK1-siRNA: LIMK1 small interfering RNA.

amino-terminal LIM domains, adjacent PDZ, proline/serinerich regions, and followed by a carboxyl-terminal kinase domain in tandem $(10,11,29)$. The LIM domains and PDZ domain are not only involved in mediating protein-to-protein 

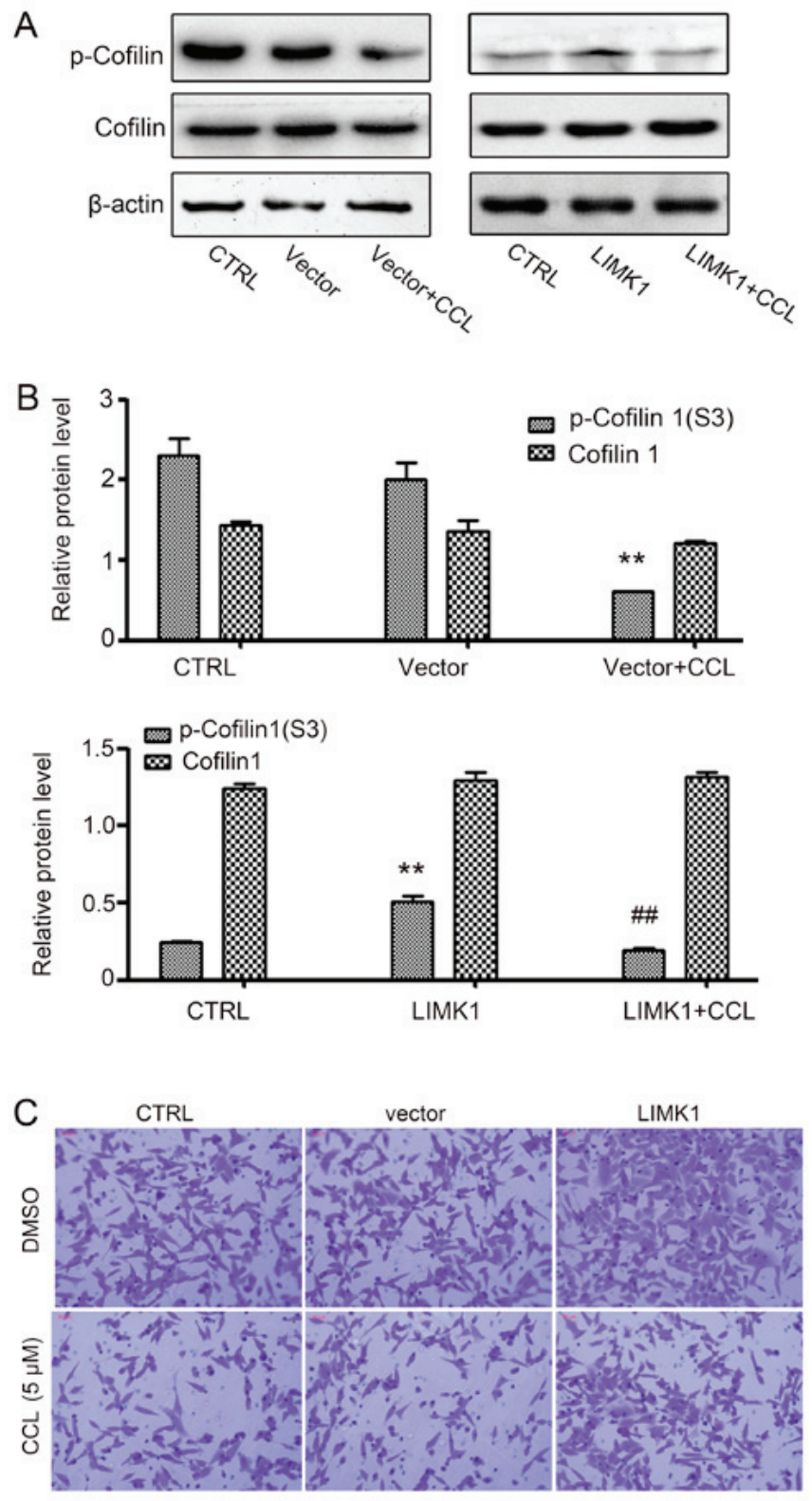

Figure 6. Overexpression of LIMK1 weakens the effects of CCL on the phosphorylation of cofilin 1 and the cell migratory capacity. (A) Overexpression of LIMK1 weakened the effects of CCL on the expression of cofilin 1 in MDA-MB-231 cells; (B) Densitometric analysis of electrophoretic bands of cofilin 1 in MDA-MB-231 cells; (C) overexpression of LIMK1 weakened the effects of CCL on the migratory capacity of MDA-MB-231 cells. Whole-cell extracts were prepared and analyzed by western blot analysis, and $\beta$-actin was used as an internal control; pIRES2-LIMK1 eukaryotic expression plasmid was used to establish LIMK1-overexpressing cells, and pIRES2enhanced green fluorescent protein empty vector was transfected into breast cancer cells as a vector control. ${ }^{* *} \mathrm{P}<0.01$ compared with the CTRL; ${ }^{\# \#} \mathrm{P}<0.01$ compared with LIMK treatments. CTRL, control; CCL, curcolonol.

interactions, but are also clearly associated with regulating LIMK activity. Studies on LIMK1 have indicated that this kinase plays a central role in regulating the architecture of the actin cytoskeleton through the phosphorylation and inactivation of cofilin family members, which leads to the reorganization of the actin cytoskeleton $(10,11)$. In addition, this kinase has been proven to be associated with the high invasion, migration and EMT of cancer cells. Studies have found that the inhibition of LIMK1 by pharmacological inhibitors and
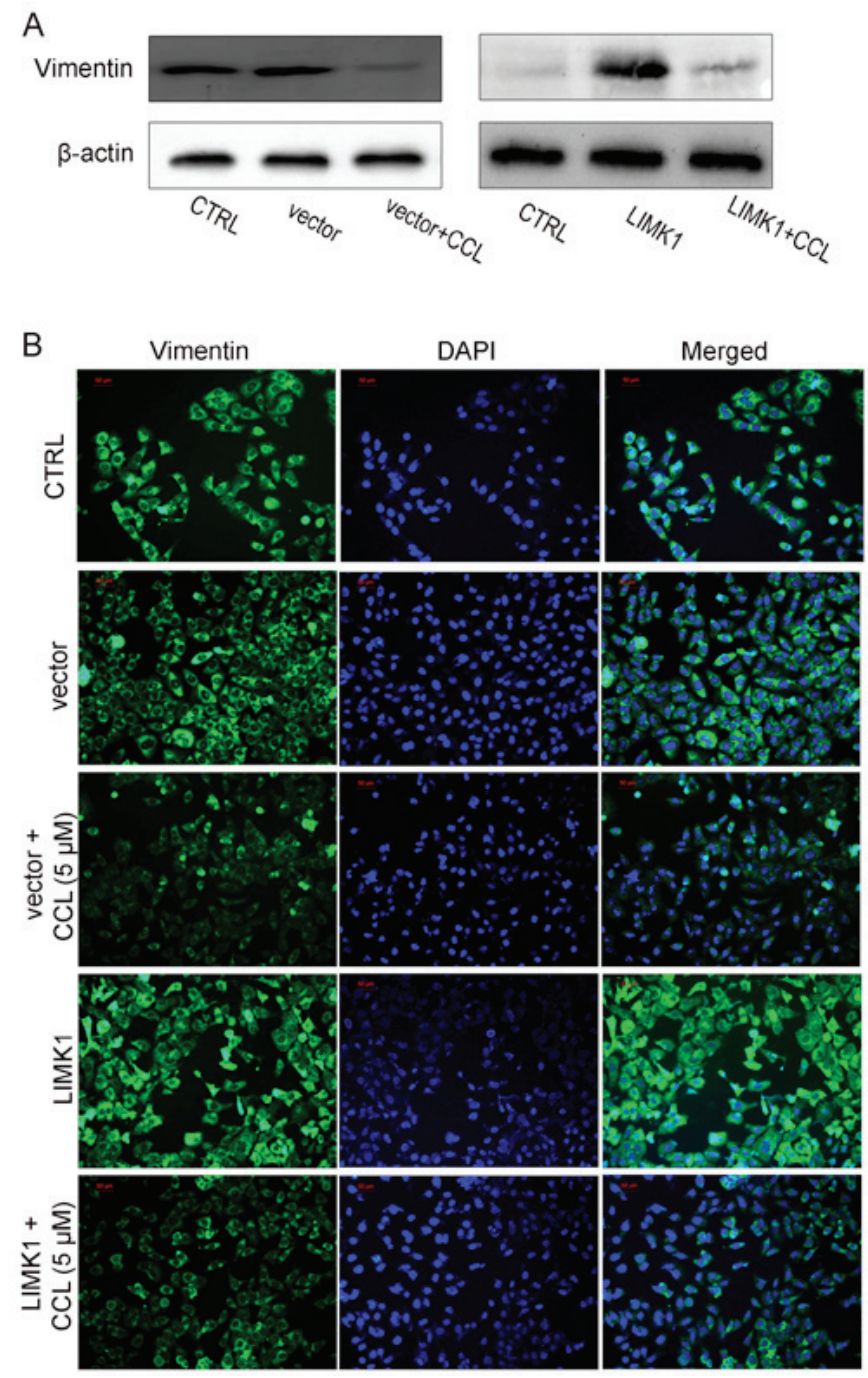

Figure 7. Overexpression of LIMK1 weakens the effects of CCL on the EMT phenotype of MDA-MB-231 cells. LIMKloverexpression enhanced vimentin expression and antagonized the effects of CCL on vimentin expression in MDA-MB-231 cells. (A) Results from western blot analysis; (B) Results from immunofluorescence assay. CTRL, control; CCL, curcolonol.

antisense RNAs targeting LIMK1 suppresses EMT, and the migration and invasion of cancer cells $(13,30)$. In this study, in order to further determine the effects of CCL on the inhibition of cofilin 1 phosphorylation, we then investigated the effects of CCL on LIMK1 expression and activation in breast cancer cells. We demonstrated that CCL significantly inhibited ATP consumption and cofilin 1 phosphorylation, but there were almost no effects on LIMK1 expression and phosphorylation. Furthermore, it was found that the inhibitory effects of CCL were attenuated when LIMK1 was overexpressed in the breast cancer cells. However, the siRNA-mediated knockdown of LIMK1 enhanced the inhibitory effects of CCL on cofilin 1 phosphorylation, cell migration and the EMT phenotype. These data suggest that targeting the catalytic activity of LIMK1 may be a mechanism through which CCL suppresses the migration of breast cancer cells, and that there may be no effects on the upstream signal transduction of LIMK1.

In conclusion, in this study, we demonstrated the antimotility properties of CCL on breast cancer cells and that these effects are due to its potential to decrease of the 

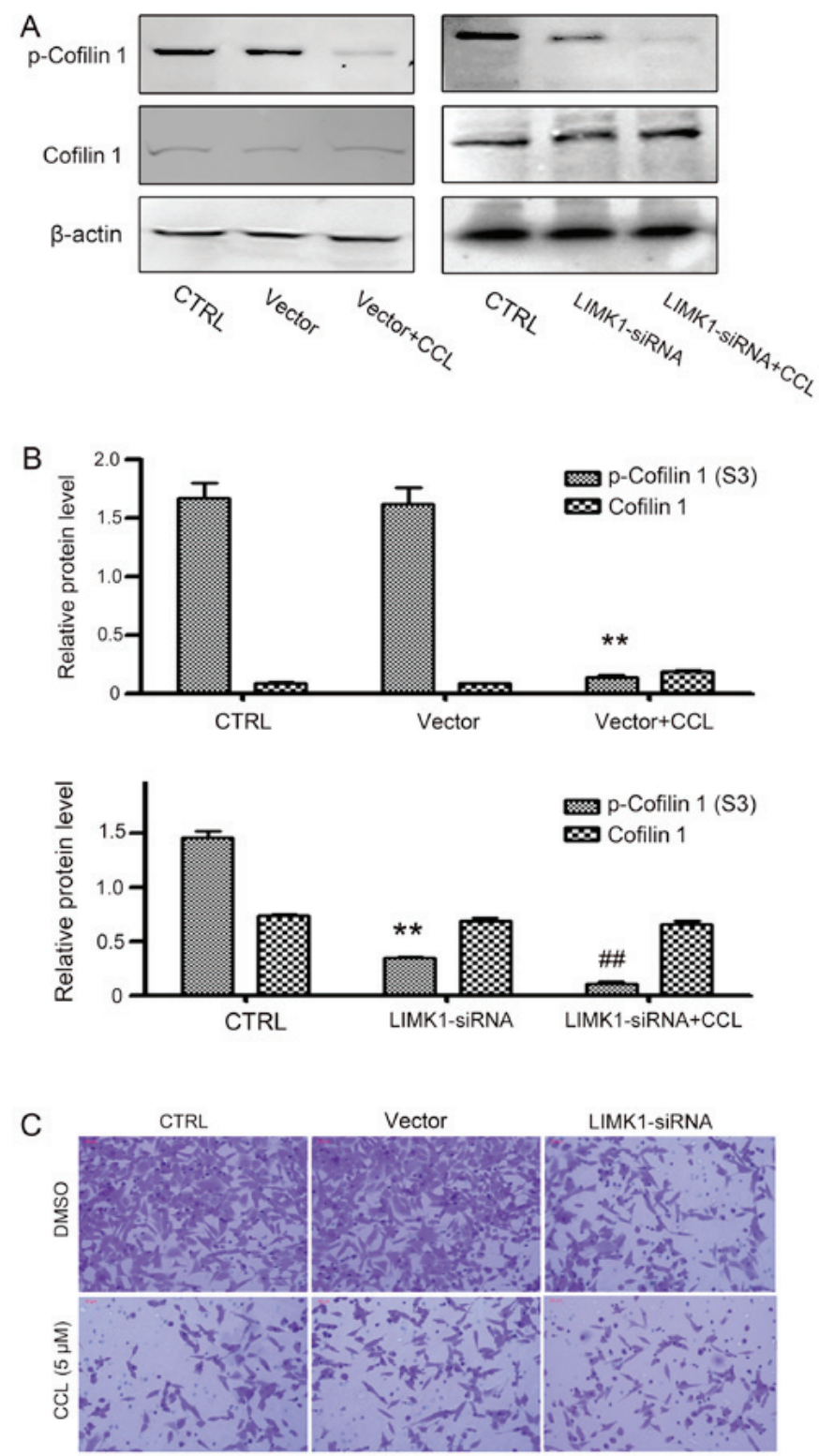

Figure 8. Knockdown of LIMK1 enhances the effects of CCL on the phosphorylation of cofilin 1 and the cell migratory capacity. (A) Knockdown of LIMK1 enhanced the effects of CCL on the expression of cofilin 1 in MDA-MB-231 cells; (B) densitometric analysis of electrophoretic bands of cofilin 1 in MDA-MB-231 cells; (C) knockdown of LIMK1 enhanced the effects of CCL on the migratory capacity of MDA-MB-231 cells. Whole-cell extracts were prepared and analyzed by western blot analysis, and $\beta$-actin was used as an internal control; siRNA against LIMK1 was used to silence the LIMK1 gene in MDA-MB-231 cells and control siRNA-1 was used as a vector control. ${ }^{* *} \mathrm{P}<0.01$ compared with the CTRL; ${ }^{\# \#} \mathrm{P}<0.01$ compared with LIMK treatments. CTRL, control; CCL, curcolonol; LIMK1-siRNA, LIMK1 small interfering RNA.

phosphorylation of cofilin 1 , which is a protein controlling the dynamics of actin filaments and the predominant substrate of LIMK1. These effects may be associated with the inhibition of LIMK1 activity. Although our data strongly indicated that the CCL-mediated suppression of cell migration was related to the inhibition of the catalytic activity of LIMK1, confirmation that LIMK1 is the direct target of CCL is still required. In future studies, we aim to focus on the molecular interaction between p-LIMK1 and CCL, and the effects of CCL on the upstream signal transduction of LIMK1.
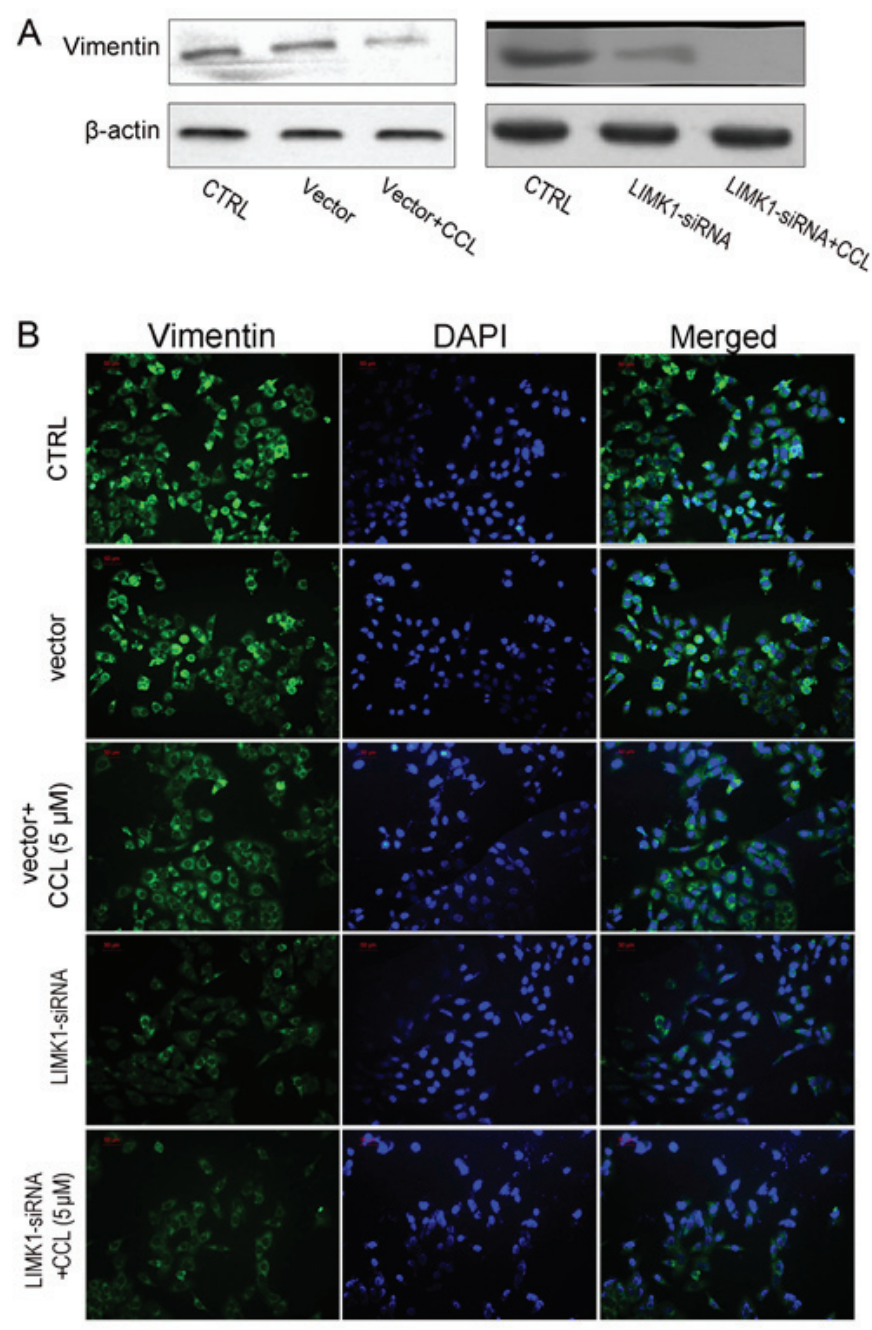

Figure 9. Knockdown of LIMK1 enhances the effects of CCL on the EMT phenotype of MDA-MB-231 cells. LIMK1-knockdown inhibited vimentin expression and enhanced the effects of CCL on vimentin expression in MDA-MB-231 cells. (A) Results from western blot analysis. (B) Results from immunofluorescence assay. CTRL, control; CCL, curcolonol, LIMK1-siRNA, LIMK1 small interfering RNA.

\section{Acknowledgements}

Not applicable.

\section{Funding}

This study was supported by Grants from the National Natural Science Foundation of China (Grant nos. 81560639, 81660680 and 81873043) and the Natural Science Foundation of Jiangxi Province (Grant no. 20171BAB205097).

\section{Availability of data and materials}

All data generated or analyzed during this study are included in this published article.

\section{Authors' contributions}

HL performed the in vitro migration assay and the Phalloidin dying of F-actin. JC contributed to experiments involving the 
overexpression of LIM kinase 1 and siRNA-mediated gene silencing. YL was responsible for the immunoprecipitation and Kinase-Glo ${ }^{\circledR}$ luminescent kinase assay. HX participated in the western blot analysis. LX performed the immunofluorescence analysis. JF was responsible for the design of this study, and the analysis and interpretation of the data. All authors read, edited and approved the final manuscript.

\section{Ethics approval and consent to participate}

Not applicable.

\section{Patient consent for publication}

Not applicable.

\section{Competing interests}

The authors declare that they have no competing interests.

\section{References}

1. Vanharanta S and Massagué J: Origins of metastatic traits. Cancer Cell 24: 410-421, 2013.

2. Chiang AC and Massagué J: Molecular basis of metastasis. N Engl J Med 359: 2814-2823, 2008.

3. Binamé F, Pawlak G, Roux P and Hibner U: What makes cells move: Requirements and obstacles for spontaneous cell motility. Mol Biosyst 6: 648-661, 2010.

4. Carlier MF, Pernier J, Montaville P, Shekhar S and Kühn S; Cytoskeleton Dynamics and Motility group: Control of polarized assembly of actin filaments in cell motility. Cell Mol Life Sci 72: 3051-3067, 2015.

5. Shekhar S, Pernier J and Carlier MF: Regulators of actin filament barbed ends at a glance. J Cell Sci 129: 1085-1091, 2016.

6. Kanellos G and Frame MC: Cellular functions of the ADF/cofilin family at a glance. J Cell Sci 129: 3211-3218, 2016.

7. Ostrowska $Z$ and Moraczewska J: Cofilin - a protein controlling dynamics of actin filaments. Postepy Hig Med Dosw 71: 339-351, 2017.

8. He L, Seitz SP, Trainor GL, Tortolani D, Vaccaro W, Poss M, Tarby CM, Tokarski JS, Penhallow B, Hung CY, et al: Modulation of cofilin phosphorylation by inhibition of the Lim family kinases. Bioorg Med Chem Lett 22: 5995-5998, 2012.

9. Prunier C, Prudent R, Kapur R, Sadoul K and Lafanechère L: LIM kinases: Cofilin and beyond. Oncotarget 8: 41749-41763, 2017.

10. Bernard O: Lim kinases, regulators of actin dynamics. Int $\mathbf{J}$ Biochem Cell Biol 39: 1071-1076, 2007.

11. Scott RW and Olson MF: LIM kinases: Function, regulation and association with human disease. J Mol Med (Berl) 85: 555-568, 2007.

12. Park GB and Kim D: PI3K catalytic isoform alteration promotes the LIMK1-related metastasis through the PAK1 or ROCK1/2 activation in cigarette smoke-exposed ovarian cancer cells. Anticancer Res 37: 1805-1818, 2017.
13. Wan L, Zhang L, Fan K and Wang J: MiR-27b targets LIMK1 to inhibit growth and invasion of NSCLC cells. Mol Cell Biochem 390: 85-91, 2014.

14. Liao Q, Li R, Zhou R, Pan Z, Xu L, Ding Y and Zhao L: LIM kinase 1 interacts with myosin- 9 and alpha-actinin- 4 and promotes colorectal cancer progression. Br J Cancer 117: 563-571, 2017.

15. Liu YH, Wu PQ, Hu QL, Pei YJ, Qi FM, Zhang ZX and Fei DQ: Cytotoxic and antibacterial activities of iridoids and sesquiterpenoids from Valeriana jatamansi. Fitoterapia 123: 73-78, 2017.

16. Editorial Committee of the Administration Bureau of Traditional Chinese Medicine: Genus Chloranthaceae. In: Chinese Materia Medica (Zhonghua Bencao). Shanghai Science \& Technology Press, Shanghai, pp2051-2061, 1998.

17. Fu J, Ke X, Tan S, Liu T, Wang S, Ma J and Lu H: The natural compound codonolactone attenuates TGF- $\beta 1$-mediated epithelialto-mesenchymal transition and motility of breast cancer cells. Oncol Rep 35: 117-126, 2016.

18. Wang W, Chen B, Zou R, Tu X, Tan S, Lu H, Liu Z and $\mathrm{Fu}$ J: Codonolactone, a sesquiterpene lactone isolated from Chloranthus henryi Hemsl, inhibits breast cancer cell invasion, migration and metastasis by downregulating the transcriptional activity of Runx2. Int J Oncol 45: 1891-1900, 2014.

19. Fu J, Wang S, Lu H, Ma J, Ke X, Liu T and Luo Y: In vitro inhibitory effects of terpenoids from Chloranthus multistachys on epithelial-mesenchymal transition via down-regulation of Runx 2 activation in human breast cancer. Phytomedicine 22: 165-172, 2015.

20. Zhang SS, Fu JJ, Chen HY, Tu LF, Xiao CR, Zhang RZ, Liu DP and Luo YM: Sesquiterpenes with anti-metastasis breast cancer activity from Chloranthus henryi. Zhongguo Zhong Yao Za Zhi 42: 3938-3944, 2017 (In Chinese).

21. Iwasa JH and Mullins RD: Spatial and temporal relationships between actin-filament nucleation, capping, and disassembly. Curr Biol 17: 395-406, 2007.

22. Meberg PJ: Signal-regulated ADF/cofilin activity and growth cone motility. Mol Neurobiol 21: 97-107, 2000.

23. Mizuno K: Signaling mechanisms and functional roles of cofilin phosphorylation and dephosphorylation. Cell Signal 25: 457-469, 2013.

24. Shishkin S, Eremina L, Pashintseva N, Kovalev L and Kovaleva M: Cofilin-1 and other ADF/cofilin superfamily members in human malignant cells. Int J Mol Sci 18: E10, 2016.

25. Wang W, Eddy R and Condeelis J: The cofilin pathway in breast cancer invasion and metastasis. Nat Rev Cancer 7: 429-440, 2007.

26. Lee YJ, Mazzatti DJ, Yun Z and Keng PC: Inhibition of invasiveness of human lung cancer cell line H1299 by over-expression of cofilin. Cell Biol Int 29: 877-883, 2005.

27. Yap CT, Simpson TI, Pratt T, Price DJ and Maciver SK: The motility of glioblastoma tumour cells is modulated by intracellular cofilin expression in a concentration-dependent manner. Cell Motil Cytoskeleton 60: 153-165, 2005.

28. Hotulainen P, Paunola E, Vartiainen MK and Lappalainen P: Actin-depolymerizing factor and cofilin-1 play overlapping roles in promoting rapid F-actin depolymerization in mammalian nonmuscle cells. Mol Biol Cell 16: 649-664, 2005.

29. Manetti F: LIM kinases are attractive targets with many macromolecular partners and only a few small molecule regulators. Med Res Rev 32: 968-998, 2012.

30. Su B, Su J, Zeng Y, Liu F, Xia H, Ma YH, Zhou ZG, Zhang S, Yang BM, Wu YH, et al: Diallyl disulfide suppresses epithelial-mesenchymal transition, invasion and proliferation by downregulation of LIMK1 in gastric cancer. Oncotarget 7: 10498-10512, 2016. 